\title{
Counting project savings - an alternative way to monitor the results of a voluntary agreement on industrial energy savings
}

\author{
Christiaan Abeelen • Robert Harmsen • Ernst Worrell
}

Received: 9 January 2015 / Accepted: 16 September 2015 /Published online: 25 September 2015

(C) Springer Science+Business Media Dordrecht 2015

\begin{abstract}
In 2008, the Dutch voluntary agreements on industrial energy efficiency faced fundamental changes to their monitoring methodology. Where the old method was based on measuring the improvement of energy use per unit of production, the new method focuses on the energy savings from projects implemented by participating companies. Advocates of the new method claim that it gives a better view of the companies' efforts to save energy, as it shows their deliberate changes in production processes, whereas opponents emphasise that the relation with 'real' energy efficiency is lost. By applying the two methods on the same group of companies, the results can be compared and show to what extent the choice of monitoring method affects the key message to policy makers. Of special interest is the relation between energy and production in the period 2008-2012, a period with large fluctuations in the level of production and energy use as a result of the economic crisis. The data show that energy-saving projects made a significant impact on energy use in the analysis period, although their effect is smaller than that of other factors such as fluctuations in production and in the number of participating companies. The old method shows a result for the period
\end{abstract}

C. Abeelen $(\bowtie)$

Rijksdienst voor Ondernemend Nederland, Croeselaan 15, 3521

BJ Utrecht, The Netherlands

e-mail: christiaan.abeelen@rvo.nl

R. Harmsen · E. Worrell

Copernicus Institute of Sustainable Development, Utrecht

University, Heidelberglaan 2, 3584 CS Utrecht, The Netherlands
2005-2013 that is less than half of that of the new method, mainly because of a decrease in efficiency during years of decreasing production. The analysis clearly shows that the two methods do not show the same development of energy efficiency improvement and should be presented as such.

Keywords Energy efficiency · Monitoring • Methodology $\cdot$ Voluntary agreements

\section{Introduction}

Industry is responsible for $28 \%$ of final energy demand in the world (IEA 2014). Since the potential for energy savings in industry is significant (Saygin et al. 2011; Cahill and Ó Gallachoír 2012a; Boßman et al. 2012), an important contribution from industry is required in order to achieve ambitious economy-wide energy efficiency goals. A number of the EU member states have introduced voluntary agreements (VAs) that aim to deliver energy savings and emission reductions via increased energy efficiency in different end-use sectors, mainly targeting industry (Rezessy and Bertoldi 2011). The VAs that have been implemented in the EU are heterogeneous. There are VAs with very specific actions that participants should undertake, whereas other VAs are more focused on targets and financial incentives (Tanaka 2011).

One of the first countries to embrace VAs as an instrument in the energy policy mix was the Netherlands, who implemented the first generation of the so-called long- 
term agreement ${ }^{1}$ (LTA1) in 1990, later followed by LTA2 and LTA3. Although LTA1 was deemed a success (Das et al. 1997), there was also criticism. Farla and Blok (2001) for example disputed the transparency of the monitoring methodology, whereas Neelis et al. (2007) found substantial differences between the results of the Dutch LTA and national statistics. LTAs have been criticised 'for deficiencies in compliance monitoring and self-reporting and difficulty in demonstrating policy additionality' (Rezessy and Bertoldi 2011, p. 7121). An analysis of two U.S. ${ }^{2}$ voluntary climate programs suggests that while voluntary programs can play some role in addressing climate change, they are unlikely to bring about the kinds of steep reductions called for in the current debate (Pizer et al. 2011). However, a study by OECD (2003) on voluntary approaches concludes that VAs are more efficient than command-and-control regulations but not as efficient as market-based instruments such as emission trading. An evaluation of the LTA3 concluded that the monitoring could be improved (Volkerink et al. 2013). Another evaluation concluded that the covenant provided value for participants in formulating new energy-saving opportunities, although the way in which results were presented could be improved (Hendriksen and van der Kolk 2013). As the LTAs are part of a mix of policy instruments, measuring and isolating their effect is challenging (Rietbergen et al. 2002).

In 2008, the Dutch voluntary agreements made fundamental changes to their monitoring methodology. Instead of measuring energy use per unit of production, the new method is based on the energy savings from projects that have been implemented by participating companies (AgentschapNL 2010a). The supposed advantage of this method is that it gives more insight in the companies' efforts to save energy as it provides a clear link between the investment in energy-saving projects and the related energy savings. However, opponents posit that the relation with 'real' energy efficiency is lost.

Because the monitoring data provided by participating companies can be used for both the old and the new methods, the results can be compared, showing to what extent the monitoring method affects the policy results.

\footnotetext{
${ }^{1}$ Here we use the term VA when referring to the instrument in general and LTA when referring to the LTA instrument in the Netherlands.

${ }^{2}$ Differences between programs in different countries originate in part from differences in company culture and organisation (Montgomery 2014). A study of the impact of these differences falls outside the scope of this article.
}

This article explains the new method and addresses its advantages and disadvantages compared to the old method. By comparing the effect of energy-saving projects with the effect of production changes, changes in sector structure, product mix and other effects, it can be established if the implemented projects have made a significant contribution to energy efficiency.

Of special interest is the relation between energy and production in the period 2008-2012, a period with large fluctuations in the level of production and energy use, as a result of the economic crisis. As the capacity utilisation of an industrial process has a significant impact on energy intensity (Boyd and Pang 2000), it is interesting to analyse how big this influence is.

This article aims to answer the following research questions:

1. What are the differences between the old and the new methods?

2. How large is the effect of energy-saving projects on energy use compared to other influences as reported in the new method?

3. Can the results of the new LTA method be compared with the old method?

4. Which method is better suited for the monitoring of a voluntary agreement?

The outline of this article is as follows: Data and methodology section starts with a literature review providing some relevant definitions. Subsequently, it describes the two different approaches to measure energy efficiency: top-down (i.e. the old method) and projectbased (i.e. the new method). Then, the dataset and methodology for this study are described in Measuring energy intensity trends in the Dutch LTAs section. Results and discussion section presents the results of the analysis. Finally, conclusions and discussion are presented in Conclusions and policy implications section.

\section{Data and methodology}

Literature review

\section{Definitions}

In general, energy efficiency is defined as the amount of energy used for a unit of useful output. Sometimes the 
inverse (output/energy) is used as well (Farla and Blok 2000).

Frequently used energy efficiency indicators are specific energy consumption (SEC) and energy intensity. The SEC is a physical energy efficiency indicator, which is sometimes also called the unit energy consumption (UEC) or physical energy intensity (PEI) (Phylipsen et al. 1997). Several authors (Worrell et al. 1994; Phylipsen et al. 1997; Boonekamp 2006; Cahill and Ó Gallachoír 2012b) reserve the term SEC for the ratio between energy and physical production $(\mathrm{J} / \mathrm{kg})$ and define energy intensity as the ratio of energy and monetary values $(\mathrm{J} / €)$. Although energy intensity is sometimes used as a proxy for energy efficiency, they are not the same. Energy efficiency refers to how efficient energy is used for a given purpose. For example, providing a similar (or better) level of service with less energy consumption on a per-unit basis is considered an improvement in energy efficiency. This unit is always physical. Energy intensity is the amount of energy use per unit of activity. Examples of activity measures are households, floor space, passenger-kilometres, tonne-kilometres, physical units of production (e.g. tonnes of steel) and sectoral value added (SVA) or gross domestic product (GDP). Energy intensity is therefore a broader measure, capturing not only energy efficiency but also other impacts on energy consumption, such as changes in the structure of the economy (Natural Resources Canada 2012).

The main choice in defining the reference system is to measure the 'useful output' in physical (e.g. tons) or economic terms $(€)$. The choice of the indicator for an activity can have a large effect on the energy intensity development (Worrell et al. 1997; Farla and Blok 2000). Freeman et al. (1997) showed a low correlation between physical and economic measures of output in industry. Physical indicators have a close relation with SEC and might improve the comparability of energy intensity indicators between countries. The use of economic indicators may serve to exaggerate year-to-year changes in efficiency. Boonekamp (2005) has produced an overview of different 'achievements' on different aggregation levels. Which unit is used best depends on the aggregation level, the unit of analysis, the complexity of products and data availability. Indicators at a macrolevel can contain many structural effects that can bias the indicators. As indicators are calculated at a more aggregated level, the influence of external factors increases. Generally, indicators measured in monetary units are applied at the macro-economic level, while physical units are applied to subsectoral level indicators (APERC 2000), obviously a consequence of data availability.

Apart from the term energy efficiency, 'energy savings' is used as well. In scientific literature, a clear distinction is made between energy efficiency and savings, but in daily language - and many policy documents as well- the terms are often used interchangeably. The fundamental difference between energy efficiency and energy savings is that energy efficiency is a relative, dimension-free ratio, e.g. $x \%$ less energy consumption per unit of output or a conversion efficiency that has been raised from 80 to $90 \%$. Energy savings on the other hand are an absolute change in energy consumption. A change in energy efficiency says nothing about the change in energy consumption or savings and vice versa. In this article, the definition of Boonekamp (2005) is used to define energy savings: the difference of actual energy use and a reference energy use. The reference energy use is the amount of energy that would have been used in the absence of energy-saving activities. In this definition, a lower energy use because of an economic recession is not defined as energy savings. Within the saving effect, one can make a distinction between autonomous savings (savings that would have been realised anyway) and policy-induced savings, which is the amount that is of interest to policy makers.

Both energy efficiency and savings can be monitored in two ways: top-down or based on project savings. Topdown monitoring was used in LTA1 and LTA2, whereas project-based monitoring is used in LTA3. These are described in the following two subsections.

\section{Old method-top-down monitoring}

Generally, top-down monitoring boils down to measuring the change in energy use between two moments in time and subsequently, using a decomposition analysis, to disentangle the different causes for that change: volume effect, structure effect and efficiency effect. The ability of aggregated indicators to measure changes in energy efficiency may be seriously compromised by other influences, like inter-industrial structural changes, techno-economic and technological effects (Eichhammer and Mannsbart 1997). As an energy intensity effect is calculated using value added data, there remains a possibility that the energy intensity changes are influenced by changes in prices (Worrell et al. 1997; Cahill and Ó Gallachoír 2012b). Therefore, the outcome 
of the top-down monitoring depends on the ability to decompose the different effects.

The energy-saving effect can be calculated by comparing the actual energy use with a reference use. Several methods exist to calculate this reference use, where choices have to be made on the selected reference system, the variable to construct reference energy consumption, the level of aggregation, interaction between saving effects, interaction with other effects and the chosen quantity to value energy consumption (Boonekamp 2006). These choices have a large impact on the outcome.

Top-down indicators can be established at different levels of aggregation, visualised in Fig. 1. The lower the level of aggregation, the more structural effects influence the results (Boonekamp 2005). A low level of aggregation gives a better understanding but requires a lot of data. Often, the chosen level of aggregation is guided by the availability of data (Farla and Blok 2000). Farla and Blok (2001) showed that many potential problems exist regarding the availability and quality of energy and production data when using physical indicators for analyzing efficiency trends in the iron and steel industry. It turned out that quite some huge mistakes had been made in energy consumption data. The accuracy in the energy intensity indicators does not allow the measurement of developments between years that lie within a close range, only for a prolonged observation period of 5-10 years (Farla and Blok 2001). The Dutch LTA1 and LTA2 used top-down indicators that were established at company level and subsequently aggregated to a sectoral level (see Measuring energy intensity trends in the Dutch LTAs section).
New method-project-based monitoring

A totally different method to calculate the effect of an efficiency program is an approach that is based on the number of projects that have been implemented. Aggregating the savings per project provides the total effect. Especially, subsidy programs use this method, as these often have detailed information regarding the projects being implemented. Examples are the Home Energy Programme in the UK (Bowie and Malvik 2005) or the Dutch EIA program (AgentschapNL 2012a), a tax deduction scheme. The difficulties with the project-based monitoring approach are the following:

- Determining the number of projects carried out by companies is labour intensive.

- Determining the exact energy-saving effect of a project is expensive and difficult to carry out without precise measurements.

- Applying correction factors for temperature, free riders, rebound effects, additionality, etc. is often debatable.

The International Performance Measurement and Verification Protocol (IPMVP) (EVO 2014) is a guidance document for measuring, computing and reporting savings on a project level. To properly document the impact of a saving measure, its energy effect must be separated from the energy effect of other conditions, like, e.g. the production level (EVO 2014). Staniaszek and Lees (2012) have developed guidelines for the calculation of savings for companies participating in
Fig. 1 Aggregation levels in energy efficiency analysis, from national efficiency down to unit operations or equipment in individual plants. From top to bottom, the analysis is performed at an ever lower aggregation level. With a lower aggregation level, the amount of data required for a comparative analysis increases (width of the pyramid). Source: Worrell et al. 1994

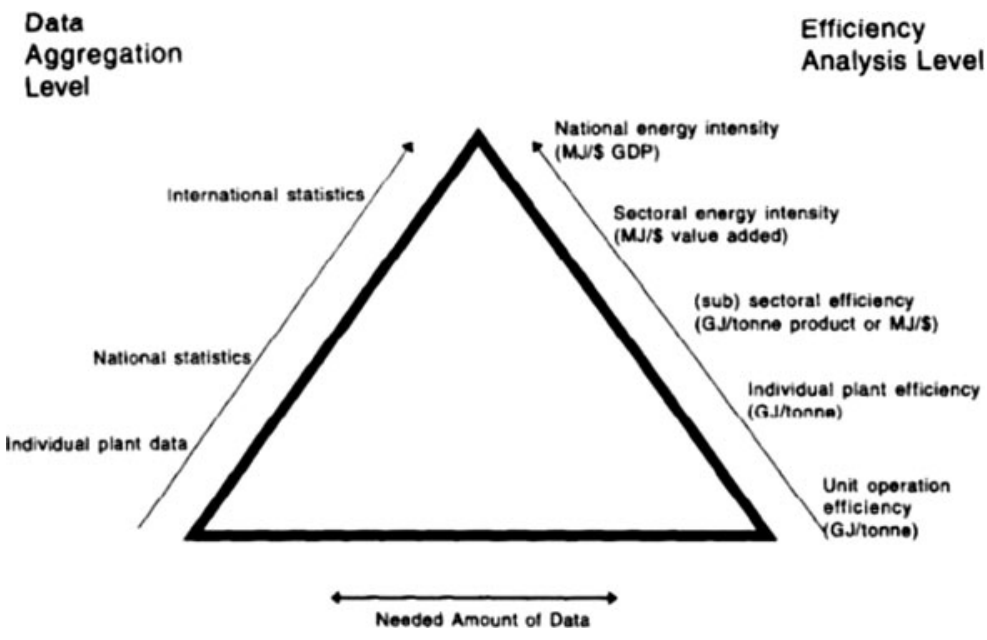


obligation schemes. For certain projects, standard values have been developed. For projects for which no standard values exist, specific calculations should be carried out. The guidelines treat various issues, i.e. rebound effect, normalisation factors and conversion factors. Also here applies the rule that the need for detailed data can lead to high costs.

The European Directive on energy end-use efficiency and energy services (European Parliament \& Council 2006), the predecessor of the Energy Efficiency Directive, has made an attempt to standardise energysaving calculations. However, it was confronted with considerable difficulties, mainly with respect to bottomup calculations, leading to non-transparent, noncomparable results. Important sources for incomparability were system boundaries, baseline definition, data quality and the application of corrections for climate factors (Leutgöb et al. 2011). The Policy and Action Standard of the World Resource Institute provides methods for estimating GHG reductions from interventions at sector or jurisdiction level (WRI 2014).

Measuring energy intensity trends in the Dutch LTAs

\section{LTA1-top-down monitoring}

LTA1 (from 1990 to 2000) used a method where the result was determined by the change in energy intensity, measured as the change in energy use per unit of production. For each individual participant, the improvement in the so-called energy efficiency index (EEI) was established. The EEI was the ratio of actual energy use and a reference energy use, the latter being the energy use if the participant would have been as efficient as in the base year (Abeelen et al. 2013), also known as 'frozen efficiency'.

The formula for the EEI is

$\mathrm{EEI}=\frac{E_{x}}{\sum_{i}\left(P_{i x} \times \mathrm{SEC}_{2005}\right)}$

where $E_{x}$ is the energy use (in joule) in year $x, P_{i x}$ is the production (in physical units) of product $i$ in year $x$ and $\mathrm{SEC}_{2005}$ is the specific energy consumption in 2005. The denominator $P_{i x} \times \mathrm{SEC}_{2005}$ is the reference energy use.

Although the EEI method was essentially the same as the method used for calculating the national saving figures for Dutch industry, based on the so-called
Protocol Monitoring Energy (PME) savings (Verdonk and Boonekamp 2009; Boonekamp et al. 2001), comparison of LTA results with national data turned out to be difficult. Apart from the difference in population size (not all companies participate in the LTA, which means that a bias effect is probable), many differences existed:

- LTA does not take into account feedstock.

- The national method uses a 3-year average.

- There are differences in reference year and systems.

Both Neelis et al. (2007) and Verdonk and Boonekamp (2009) found that reported LTA savings were much higher than PME savings, even when methodological differences like the incorporation of feedstock energy were corrected: while LTA2 reported an average EEI improvement of $1.5 \%$ /year over 20012007, PME calculated an improvement of $0.8 \%$ year. This difference could mainly be explained by the selfselection effect (companies with a small saving potential will not participate in LTA) and the fact that large, energy-intensive companies did not participate in LTA2 (Verdonk and Boonekamp 2009). Ramirez et al. (2005) calculated the energy intensity of the Dutch food industry (responsible for $9 \%$ of final energy use) using physical production data of National Statistics. Their results showed a difference of only $4 \%$ compared to the Dutch LTA. However, Neelis et al. (2007) found substantial differences between LTA1 data and national statistics in the paper, iron/steel and chemical industry. The critique echoed that of Farla and Blok (2002), who stated that 'LTA monitoring does not ensure a comparable and objective monitoring of the energy-intensity results', 'the monitoring is insufficiently transparent' (p. 165) and 'differences with national statistics cannot be explained satisfactory’ (p. 173).

\section{LTA2 - top-down monitoring}

The monitoring method used in the Dutch LTA2 (20022008) applied a broader saving definition. Next to process efficiency (based on the EEI approach), also savings in the production chain and fossil fuel savings from renewable energy production were counted as savings. The latter two were based on the effects of individual projects and expressed in two separate indices (AgentschapNL 2009a). In this way, companies were rewarded for their other efforts as well. However, this led to a suboptimal, too complex presentation of results, 
which was not very transparent for participants (AgentschapNL 2010b). The main objection of participants to the EEI method was that the change in EEI was heavily influenced by other factors than the actions of the companies alone, for instance by capacity utilisation, temperature and product specifications, and therefore did not give a good presentation of the efforts of covenant participants (AgentschapNL 2010a).

When this was recognised, discussion started to improve the method (AgentschapNL 2009a). One option would have been to exclude structure effects and other effects that had nothing to do with the efforts of firms to save energy. Some sectors already tried to correct for some of these effects. This option was offered in the old monitoring method by using so-called 'correction factors'. A motivation to use these correction factors would be to exclude negative effects that were out of the sphere of influence of companies ('external' effects). Companies could only correct for external effects, not for effects they had caused themselves (e.g. an increase in energy use because of an extra process step to alter product specifications). The Dutch ceramics industry corrected for example for changes in the product mix, and the potato processing industry corrected for changes in dry-matter content (AgentschapNL 2009b). Although the total effect of corrections remained small, this system created an imbalance between sectors, as not all sectors - or all companies within a sector - applied correction factors. Another problem was to determine which factors to correct for and to determine the level of corrections. Corrections tended towards better results, indicating a possible unfairness, as was already observed by Farla and Blok (2002). The applied corrections made it also more difficult to define the 'real' effect, creating even more of a 'black box'. Therefore, the method of corrections was discharged as being too complicated (Abeelen et al. 2013).

\section{LTA3_project-based monitoring}

Instead, the partners in the LTA decided for a projectbased method which was assumed to better visualise the efforts of the participants, i.e. to count the effect of all energy-saving projects implemented by the participants. An important part of the LTA is that participants make an energy efficiency plan (EEP) every 4 years. In this EEP, they plan which energy-saving projects to implement in the next 4 years. All projects with a payback period of less than 5 years should be implemented. The result of the agreement was formulated as the degree to which the planned projects have been implemented. In simple terms: has a company done what it promised to do? The method is described in AgentschapNL (2010a). Measures fall in three distinct categories: (1) process efficiency, (2) chain efficiency and (3) renewable energy (NL Agency 2008). For this article, only measures in the category 'process efficiency' are assessed. This category is directly linked to the energy use of the company itself. $^{3}$ Process efficiency measures can be placed in four subcategories. Table 1 shows examples of the four subcategories. In Abeelen et al. (2013), the realised savings per subcategory are presented.

In annual monitoring reports, companies report which projects they have actually implemented and how much energy these projects saved (in joule). Guidelines for these calculations are given in the 'Handbook monitoring' (AgentschapNL 2012b). The relative saving effect is calculated as

$\operatorname{RS}_{x}(\%)=\frac{\mathrm{AS}_{x}}{\left(E_{x}+\mathrm{AS}_{x}\right)}$

where $\mathrm{RS}_{x}$ is the realised saving as a percentage of total energy use in year $x, \mathrm{AS}_{x}$ is the actual savings in joule in year $x$ and $E$ is the primary energy use in joule in year $x$. Final energy use was converted into primary energy using default conversion factors as defined by Vreuls and Zijlema (2013), the most important factors being $31.65 \mathrm{MJ} / \mathrm{m}^{3}$ for natural gas and $9 \mathrm{MJ} / \mathrm{kWh}$ for electricity (assuming a $40 \%$ conversion efficiency).

The denominator $\left(E_{x}+\mathrm{AS}_{x}\right)$ is the reference energy use in the definition of Boonekamp (2005): the energy used if the project would not have been implemented. The factor $\mathrm{AS}_{x}$ in the denominator is added because the

\footnotetext{
$\overline{3}$ The second category is chain efficiency. These measures improve energy efficiency not within the own company but elsewhere in the production chain from raw material to end use and the energy supply needed for that purpose. Chain efficiency can be improved by improving performance, reducing the amount of materials needed, more efficient transport of goods and products, savings during the phase of product use (lower energy consumption or life cycle extension) or savings arising from efficient and effective disposal of products (reuse, recycling, the use of material for energy generation). For LTA companies, renewable energy is also an option as third category. These measures do not save energy use per se but only fossil energy use and thereby 'green' the energy use of the company. All three categories contribute to the result, and a certain trade-off between the categories is possible. However, adding the results could lead to misinterpretation as the two extra categories have no relation to actual energy use or efficiency.
} 
Table 1 Subcategories of process efficiency measures

\begin{tabular}{ll}
\hline Subcategory & Example \\
\hline $\begin{array}{c}\text { Energy management and } \\
\text { good housekeeping }\end{array}$ & $\begin{array}{l}\text { Awareness campaigns } \\
\text { Monitoring system } \\
\text { Improvement of maintenance } \\
\text { programs }\end{array}$ \\
& $\begin{array}{l}\text { New machines } \\
\text { Different process setting } \\
\text { (temperature, pressure, etc.) }\end{array}$ \\
& $\begin{array}{l}\text { New process design } \\
\text { Efficient lighting }\end{array}$ \\
Utilities and buildings & Insulation \\
& Combined heat and power (CHP) \\
& New production plants \\
Rtrategic measures & Replacements \\
& Change in product mix
\end{tabular}

Source: Abeelen et al. (2013)

energy use in the reporting year is the energy use after implementation of the project (Abeelen et al. 2013).

All monitoring reports are checked for completeness and correctness by external consultants. This check is basically a probability check: by comparing the development of energy use with production and project data, they assess if the reported data are correct, using an analysis comparable to the one presented in Comparison of old and new methods section.

\section{Data sources}

All companies participating in the Dutch LTAs send annual monitoring reports to RVO.NL, which processes and analyses the data. Table 2 gives an overview of available data. For this article, only data from LTA3 are used, as this dataset is consistent over the longest period (2005-2013).

To make a sound analysis of production and energy data, a comparison was made of the development of energy use and production on company level, to establish completeness and quality of these data. First, all companies without industrial processes were excluded: hospitals, universities and higher education, financial services and datacentres. For these companies, 'production' has to be defined on other grounds than for industrial processes. Secondly, as will be explained in Energy use 2005-2013 section, there is a very large influence of companies joining or leaving the LTA. To eliminate this influence, 245 companies that have only participated for part of the period 2006-2013 were excluded from the
Table 2 Available monitoring data (annual base)

\begin{tabular}{|c|c|}
\hline Theme & Available data \\
\hline Energy & $\begin{array}{l}\text { Purchase, production and sale of energy } \\
\text { carriers (electricity, heat, gas and other } \\
\text { fuels) in } \mathrm{kWh}, \mathrm{m}^{3} \text {, tonnes, etc. }\end{array}$ \\
\hline Production & $\begin{array}{l}\text { Production in physical units or an index } \\
\text { for LEE participants }\end{array}$ \\
\hline Saving projects & $\begin{array}{l}\text { Implemented saving projects } \\
\text { - Title of the project } \\
\text { - (Sub)category (see Table 1) } \\
\text { - Certainty level (certain, conditional } \\
\text { and uncertain) at moment of planning. } \\
\text { - Year of implementation } \\
\text { - Expected saving (at the moment of } \\
\text { planning) (in joules) } \\
\text { - Realised saving, in units of avoided final } \\
\text { energy use (in joules) } \\
\text { - If necessary, an explanation is added }\end{array}$ \\
\hline Influencing factors & $\begin{array}{l}\text { Other factors influencing energy use that } \\
\text { are not defined as saving projects, i.e. } \\
\text { climate, changes in factory design and } \\
\text { product specifications }\end{array}$ \\
\hline Energy management & Status of energy management \\
\hline
\end{tabular}

analysis. Thirdly, it was checked whether the unit of performance for the underlying production data was consistent for the whole period ${ }^{4}$.

\section{Analysis steps}

For answering the first research question, the old and the new methods, as described in Measuring energy intensity trends in the Dutch LTAs section, are compared qualitatively, based on the general principles, the input data used and the calculation results.

The second research question required several steps.

- The first step was an analysis of the development of energy use, based on the energy consumption data

\footnotetext{
${ }^{4}$ As the new reference year 2005 was agreed upon in 2008, companies had to re-establish the reference energy use in 2005. For most companies, this was done correctly, but for a small number of companies, it was not possible to establish a consistent production data set for the whole period. Problems can occur because companies have made calculation errors or because they have merged or split different production units for different product groups, e.g. first one unit for all products and later one unit for fresh products and one for frozen products. Although this concerns only 43 companies, the effect is about as large as the effect of population changes, as the large oil- and gas-producing companies are among this last group.
} 
reported by the participants in their monitoring reports. Final energy use was converted into primary energy using default conversion factors as defined by Vreuls and Zijlema (2013).

- The second step was an analysis of the development of production. Production was visualised in the form of a reference energy use. This reference energy use was calculated by multiplying the physical amount of production with the specific energy consumption in 2005:

$E_{\mathrm{ref}, x}=\sum\left(P_{i x} \times \mathrm{SEC}_{2005}\right)$

where $P_{i x}$ is the production in physical unit (ton, $\mathrm{m}^{2}$, etc.) of product $i$ in year $x$ and SEC is the specific energy consumption in 2005 ( $\mathrm{J} /$ ton). Companies can define their own unit of production. About two thirds of the participating companies use one unit of production for their total production; the rest have different units for different products or product groups. A company could decide to merge several products in one product group. For instance, a meat producing company could choose to use two product groups, one for all fresh meat products and one for all frozen products. The resulting reference energy use is the amount of energy that would have been used if production was as efficient as in the reference year. If the real energy use is lower than the reference energy use, production has become more efficient. The ratio of the reference use in 2 years is used to calculate the volume effect:

$$
V=E_{x} \quad \times\left(\frac{E_{\text {ref }, x}}{E_{\text {ref }, x}{ }^{-1}}-1\right)
$$

- Third, the effect of all implemented energy-saving projects and other influencing factors that have been reported in the monitoring reports is counted.

- The last step is a combination of all abovementioned developments, to establish if the combined effects add up to the change in energy use. A too large gap between the added effects and the actual change in energy use is a sign of inaccuracy.

For the third research question, the EEI was calculated according to the old method and compared to the results of the new method (savings), in order to see the difference in outcome of the two methods.
For the last research question, a comparison was made between the original reasons for the change in methodology and the findings in the different evaluations that have been executed by the LTA board.

\section{Results and discussion}

Energy use 2005-2013

Figure 2 shows the development of the energy use of the industrial companies participating in LTA3. Total primary energy use covered by LTA3 has risen from 147 PJ in 2005 to $199 \mathrm{PJ}$ in 2013. However, the number of companies participating was not consistent over this period. In 2005, 762 companies participated, in 2013 847. In total, 244 companies newly joined LTA3 in this period, notably 20 large chemical companies, 73 companies from the animal feed industry and 22 municipal waste companies. In the same period, 159 companies left. There are also 29 companies that joined but left after a few years. In most cases, the reason for leaving the agreement was a shutdown of the production plant, although some companies chose to leave for other reasons. Overall, the composition of the LTA3 population has changed considerably during this period. As new companies were on average larger than companies leaving the covenant, the net effect of population changes is an increase of the covered energy use by 45 PJ. This explains the largest part of the increase of the total energy use between 2005 and 2013 of 52.1 PJ in Fig. 2.

Figure 2 also shows the energy use of only those companies that have reported complete and consistent energy and production data for the whole period 20052013. This accounts for about $60 \%$ of the energy use from all participants. Besides the large effect of companies that have reported only part of the period, a large effect is the exclusion of the oil- and gas-producing industries (37 PJ). As this sector has used a particular method for part of the period, it is not possible to provide a good comparison of energy use and production level. So, the effect of population changes and incomplete reporting is very substantial.

From Fig. 2 can be derived that the total energy use of the companies that participated and reported energy data for the full period (energy use* in Fig. 2) decreased from $89 \mathrm{PJ}$ in 2005 to $83 \mathrm{PJ}$ in 2013. The next paragraphs will explain the reasons behind this decrease. 
Fig. 2 Development of primary energy use (without energy use for feedstock) and number of participants of LTA3 2005-2013. Energy use depicts all participating companies. Energy use* depicts only those companies that have participated and reported energy data for the complete period $(n=559)$

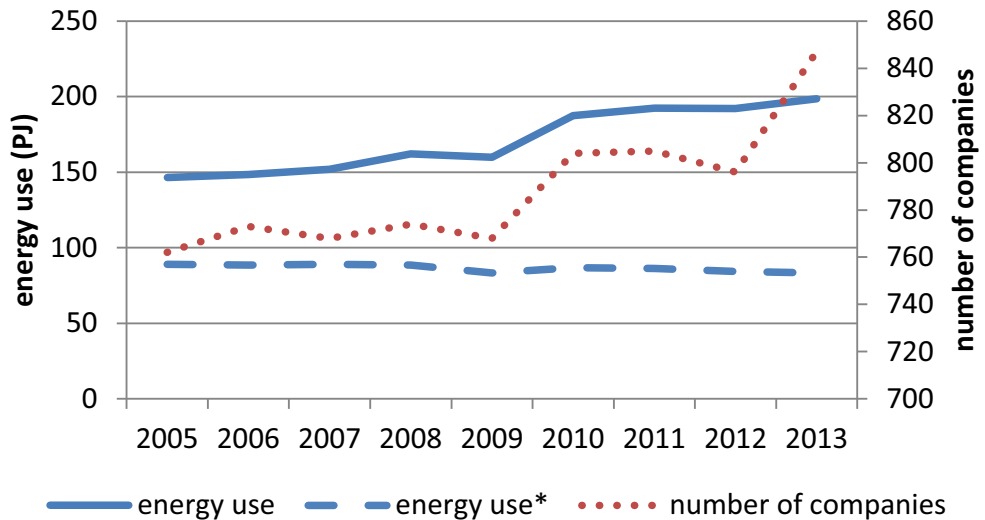

Production 2005-2013

Figure $3^{5}$ compares the energy use with a reference energy use: the theoretical energy use if production would have been as efficient as in 2005. The change in the reference energy use represents the volume effect: the effect of the change in production levels.

As Fig. 3 shows, the actual energy use has decreased more than the reference energy use, indicating a decrease of the energy intensity. The larger the difference between actual and reference energy use, the larger the change in efficiency. The figure clearly shows the large drop in energy - and production levels in 2009, a result of the economic crisis. Especially, the sectors supplying to the automobile industry and building construction sector show large fluctuations in production. The years 2010 and 2011 show partial recovery, but 2012 shows another decrease in production levels. Usually, during a decrease in production, energy intensity increases. The reason for this effect is that part of the energy consumption (offices, cleaning, start-up energy use, etc.) has no direct relation with production levels. As this 'basic energy use' is used for a smaller amount of products, energy intensity increases. The larger the share of basic energy use, the larger this effect. This effect is visible in Fig. 3 as the gap between the actual and reference energy use becomes smaller in 2009. Grobler (2010) has described this phenomenon and concludes that energy intensity should therefore not be used to determine savings. Normalizing for this phenomenon is possible,

\footnotetext{
${ }^{5}$ National Statistics have a statistic on capacity use for industry (Conjunctuurenquete). Although it is based on a sample of companies, their trend gives a reasonable good match on our production figures: over the same period, they find capacity use decreased $3.0 \%$.
}

but requires detailed data, at least on company level but preferably on installation level. This level of detail is not available in the LTA data.

Overall, the production level in 2013 (calculated with Eq. 3) is $0.9 \%$ lower than in 2005 . The net effect of the decrease of production is therefore relatively small: 0.24 PJ of the 6 PJ decrease in energy use can be explained by lowered production. It should however be noted that the gross effect of production changes is much larger than the net effect, because fluctuations between different years level out to a certain extent and because growing production in one company in a specific year can be compensated by decreasing production in another company in the same year.

Energy-saving projects 2006-2013 and other influencing factors

Companies participating in the LTA have to report all energy-saving projects that they have implemented. By definition, these have a decreasing effect on energy use. From 2006 to 2013, the companies in the observed dataset have reported a total of 13.1 PJ savings. The new method calculates a saving index, an index based solely on the savings caused by energy-saving projects. This index is 86.1 for 2013 , showing savings of 13.9 or $1.9 \%$ per year.

As the results of a company are dependent on selfreporting, there might be reasons to expect companies to overreport realised savings. Especially, companies who score badly will feel stimulated to report more savings than have actually been implemented, therefore making it probable that too many savings will be reported. Yet, there are very few examples of projects 
that have been reported but turned out not to be implemented, while there are known cases of projects that have been implemented but not reported. ${ }^{6}$ Sometimes companies forget to report projects: for instance in the case of smaller projects, sometimes companies report that a project has been implemented but cannot quantify the savings and therefore report zero savings. Therefore, it seems reasonable to expect overreporting and underreporting to compensate each other and the inaccuracy on an aggregated level will be small. On the one hand, production data are more accurate than project data, as production data are the centre of attention of all production plants and information on production efficiency is key to profitability. Therefore, most plants have extensive systems monitoring key features of the production process. On the other hand, project data are more difficult to collect. For few projects, actual savings can be measured; for most projects, it is only possible to estimate the realised savings. A study on the accuracy of data in the Danish Energy Efficiency Obligation found a relatively small discrepancy of $6 \%$ between the savings $(\mathrm{kWh})$ reported by the obligated parties and the estimated actual savings (kWh) measured (Bundgaard et al. 2013). Still, to check if the saving effect is indeed accurate, it is necessary to perform a sample review of projects, or production data are needed to compare the saving effect with other effects and with a baseline. Such a consistency check is a systematic part of the check on monitoring data that is performed by external consultants.

Part of the reported projects would have been implemented regardless of the agreements but should be attributed to other policy instruments or autonomous savings. Quantitative evidence for additional effects of the agreements is limited. First of all, there is a lack of baselines against which to assess agreements. Secondly, it is difficult to disentangle the different instruments. In most cases, factors other than the voluntary approach seem to explain the major part of any

\footnotetext{
${ }^{6}$ For instance in the case of the metallurgic industry of 2012, see http://www.rvo.nl/subsidies-regelingen/sectorrapportagesindustriële-sectoren. An analysis of 27 companies that did not report all certain planned projects for 2013 revealed four companies that had implemented these projects but had not (yet) reported them. An analysis of 128 projects that had been reported with a zero saving revealed 16 projects for which savings could not be calculated.
}

environmental improvement. Based on estimates from other studies ${ }^{7}$, it is possible to conclude that less than half of the reported savings are additional.

\section{Other influencing factors}

Besides the effect of production and energy-saving projects, other factors can have an effect on energy use as well. This can be yearly recurring effects like climate effects or special occasions like the introduction of new products, incidents in the production facility or deliberate changes in the facility. These factors can have either saving or dissaving effects on energy consumption. If applicable, LTA3 companies have to report these factors if production volume changes and/or energy-saving projects alone do not explain the change in energy use. Overall, companies have reported influencing factors that have a net increasing effect of 10.5 PJ. As with the volume effect, the gross effect of these factors is much larger (31.9 PJ), as increasing and decreasing effects mitigate each other.

\footnotetext{
${ }^{7}$ An evaluation of the Danish Energy Efficiency Obligations in 2012 was able to determine that the net savings impact of the Danish Energy Efficiency Obligation is about a third of the reported savings. Additionality appeared to be $52-60 \%$ for industry (Bundgaard et al. 2013). By comparing company-level savings in the Irish Large Industrial Energy Network (LIEN) to total industry savings (calculated using a top-down method), it could be estimated that $38 \%$ of total savings could be attributed to participation in the program (Cahill 2012a). An analysis of seven VAs by Vreuls et al. (2005) found that around $50 \%$ of efficiency improvement could be credited to the program. Rietbergen et al. (2002) used two methods to isolate the impact of LTA1, the first Dutch agreements on energy efficiency. Through a combination of expert judgement and a survey, it was found that $27-44$ or $29-44 \%$ respectively could be attributed to the implementation of LTA1. The most recent evaluation of LTA3 concludes that the effect of the agreements as a separate instrument is difficult to establish, but several studies, based on surveys and interviews, mention an additionality of $50 \%$ (Volkerink et al. 2013). A large part of the reported savings could be attributed to other policy instruments, but it is very hard to attribute savings to a specific instrument when multiple instruments are in place simultaneously. A part of the reported savings could also be attributed to autonomous savings, savings that would have occurred anyway, and therefore should officially not be counted as saving effect in the definition of Boonekamp (2005). It is difficult to determine exactly how large this autonomous savings are. A recent evaluation of the long-term agreements for ETS companies concluded that $86 \%$ of respondents claimed that the agreements were '(very) important' for implementation of energy-saving projects, but at the same time, $64 \%$ of respondents stated that $80 \%$ or more of those projects would have been implemented anyway (Hendriksen and van der Kolk 2013).
} 
Fig. 3 Development of energy and reference energy use 20062013 for industrial LTA companies $(n=559)$. Reference energy use is calculated using Eq. 3

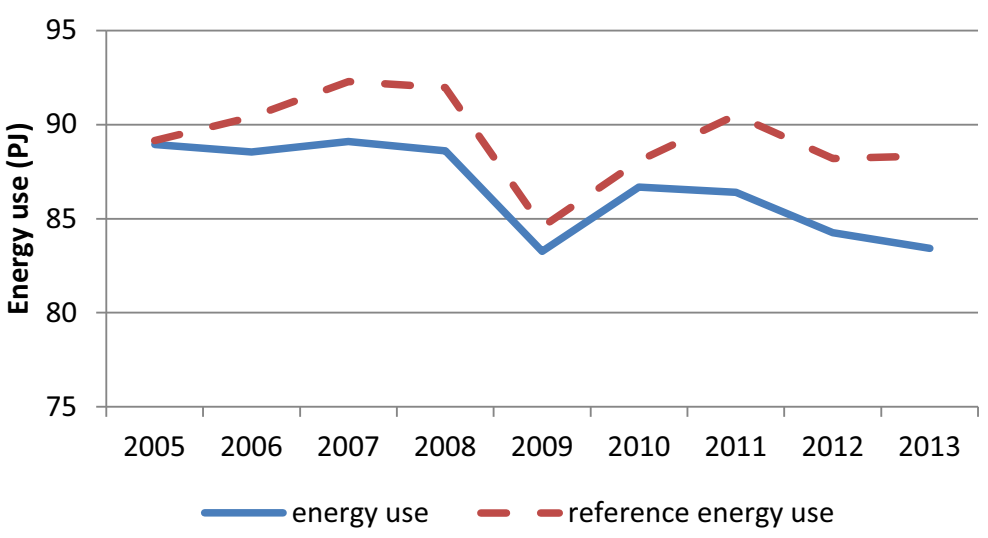

Decomposition analysis

If the results of Production 2005-2013, Energy-saving projects 2006-2013 and other influencing factors and Other influencing factors sections are combined, Fig. 4 can be drawn. This figure is not based on a formal decomposition method but on a bottom-up inventory of the drivers of energy use, as reported by the LTA participants. The first bar shows the energy use in 2005 and the last bar the energy use in 2013. The bars in between show the net effect of respectively energysaving projects, production changes, other influencing factors and an unexplained factor. The effect of saving projects is the total effect of all energy-saving projects reported in this period. The effect of production changes is based on physical production data, using Eqs. 3 and 4 (see Production 2005-2013 section). The effect of 'other influences' is the total of all other factors that have been reported by companies (i.e. climate and product specifications). The last 'unexplained' factor is the difference between the first six columns and the actual energy use in 2013. If this residual is too high, it is an indication of errors in the composition of the other factors: inaccuracies, missing factors, projects that have not been reported, etc.

Figure 4 shows a large difference between gross and net effect of the volume effect and the effect of other influences. In both cases, saving and dissaving effects partly compensate each other. Although the net effect over this period is small, the total effect of production is several times larger than the effect of energy-saving projects. This also holds for the effect of 'other influences'. Because this figure is based on a fixed population, the effect of population changes is filtered out. As was observed in Energy use 2005-2013 section, the effect of increasing LTA population in this period was $45 \mathrm{PJ}$, which is larger than any of the other effects.

Comparison of old and new methods

By comparing the energy and production data, the EEI can be calculated, as was done in the old method. The development of this index is shown in Fig. 5. The EEI for 2013 is 94.4, which means a decrease in the amount of energy used per unit production of $5.6 \%(0.7 \%$ per year). It shows a gradual decrease in most years but an increase in 2009 and 2012 (although much smaller in the latter). This increase corresponds with the decline in production in 2009 as a result of the economic crisis. Because of lower capacity utilisation, the amount of energy used per unit of production rises. The saving index in the new method shows savings of $13.9 \%$ in 2013 or $1.9 \%$ per year.

When comparing the two indices, two differences can be observed. First, the saving index shows on average a higher result than the EEI, although in some years, the EEI decreases faster than the saving index. Second, the saving index shows a more gradual development than the EEI, at least at an aggregate level. At the level of individual companies, there are large differences: some companies have implemented measures that save up to $50 \%$ or more than $5 \%$ per year. These large savings typically come in large steps, when major installations are replaced. Therefore, there are also large variations from year-to-year savings, at least at company level. At sectoral level, the differences between sectors are smaller but still quite large. Aggregated to the level of more than 500 companies as shown in Fig. 5, differences between years are levelled out. On the contrary, the EEI shows large fluctuations from year to year, even 


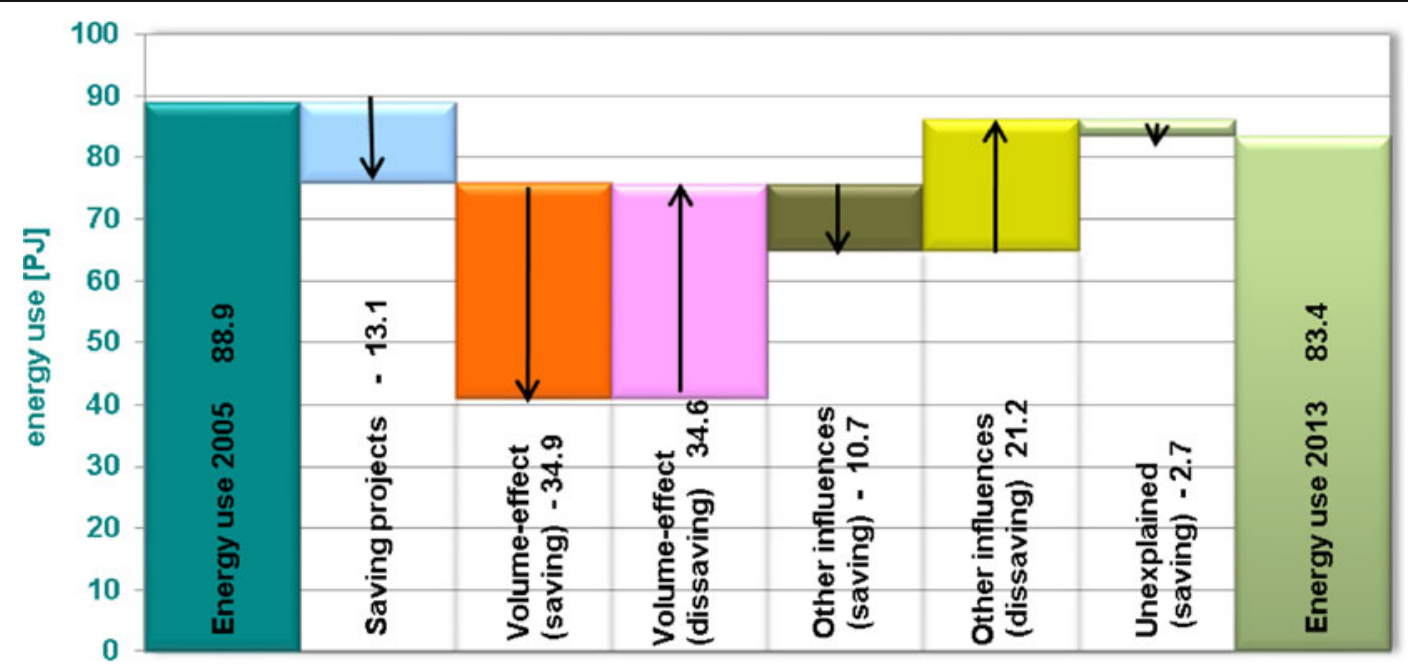

Fig. 4 Explanation of the change in energy use between 2005 and 2013

at an aggregated level. Year-to-year changes of the EEI range from -3.0 to $+2.1 \%$. This raises the question what conclusions can be drawn from this study period but also offers an opportunity to visualise the effect of the economic crisis on the EEI.

The reason behind both differences is the high dependency of the EEI on production changes. This is shown most clearly in years of production decreases. However, also in years of fast-growing production, the EEI usually shows a higher decrease. The development of the EEI clearly shows the effect of the economic crisis, with production decreases in 2009 and-to a smaller extent, 2012. The economic crisis also has an impact on implementation of energy-saving projects, as investments go down. However, this effect is much smaller. In difficult economic periods, companies are more focused on efficiency than normal. Moreover, a forced temporary production stop can be an opportunity for maintenance on installations that would otherwise have to wait for planned maintenance, accelerating technological innovation.

A working group of the LTA board concluded that the new method provided a better indication of the efforts of participants to save energy. However, some sectors indicated that they wanted the old EEI method presented next to the result of the new method, to keep track of the development of energy used per unit production and to be able to compare the results of the old and the new methods (AgentschapNL 2011a, b). As true as this might be, the new method still does not tell if these efforts are a result of a policy instrument or not.

A fundamental difference is that the result in the new method cannot be negative, as was sometimes the case in the old method. In the new method, the minimum result is zero (in the situation that no company reports any implemented projects). Even when a previous
Fig. 5 Development of energy efficiency index (EEI) (old method) based on energy intensity versus saving index (new method) based on implemented saving projects for all industrial LTA companies

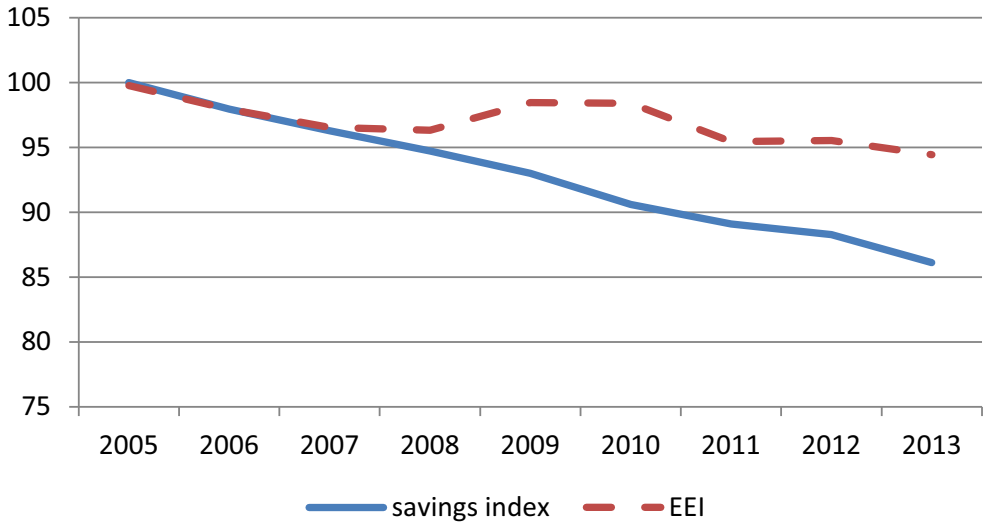


saving is $\operatorname{lost}^{8}$, this dissaving effect will be reported as an influencing factor and have no effect on the result.

\section{Conclusions and policy implications}

This section provides an answer to the research questions that were formulated in the Introduction.

Q1: What are the differences between the old and the new methodologies?

The main difference is the fact that the result in the new method is determined only by reported savings and not calculated on reported production and energy data. The new method therefore uses different input data. The reported savings in the new method are not influenced by volume or structure effects. Especially, the effect of production changes had a large impact on the result of the old method, particularly in the period of the economic crisis. Although this effect represents an actual change in energy intensity, the effect does not represent structural savings, as the change in energy intensity is reversible. The new result, aggregated over all companies, shows much less variation from year to year, showing the independence to external influences. A fundamental difference in output is that the result in the new method cannot be negative, as was sometimes the case in the old method. In the new method, the minimum result is zero.

Q2: How large is the effect of energy-saving projects compared to structural change and volume developments and other influences?

Companies might be tempted to assign a decrease in their energy use to projects they have implemented, but in practice, other factors are more important. The analysis in Decomposition analysis section demonstrates

\footnotetext{
${ }^{8}$ Incidentally, projects that have been reported are being decommissioned, i.e. when it appears that product quality is being affected. This does not happen often, as in most of these cases, the project is stopped before it is reported in the monitoring reports. A more substantial 'dissaving' occurs with good housekeeping measures, whose effect usually lasts less than 3 year (CEN 2007). Companies are requested to report these kinds of measures only once, but this rule is difficult to uphold. Therefore, it is likely that the reported savings under this category are an overestimation. As this is the smallest category, the total effect is not big but could be $0.1-0.2 \%$ annually (Abeelen et al. 2013).
}

that energy-saving projects play a significant role in the change in energy use, but their effect is smaller than the effect of other factors. Yet, because other factors can have both increasing and decreasing effects on energy use, the net effect of these factors is smaller. By definition, energy-saving projects have only a saving effect. Still, the effect of implemented projects helps to explain the change in energy use: if the saving effect would not have been included, a larger residual would remain. Therefore, it is safe to conclude that the implementation of energy-saving projects does have an impact on energy use, as well as on energy intensity.

By far, the largest driver for changes in energy use in individual companies is a change in production level. Only in special occasions other factors are more important. Because production levels can go up and down, the net effect of production changes is small in the period 2006-2013, while the effect in the intermediate years is several times larger than the other factors. A different study period would give different results.

A comparison of production and energy data (Production 2005-2013 section) shows the importance of good design of the unit for production. The change in the reference year has introduced errors in a small share of companies. Changes in methodology distort the results for these companies, making long-term analysis of their specific energy consumption impossible.

\section{Q3: Can the results of the new LTA method}

be compared with the old method?

The most essential question is whether the two methods provide comparable results. The answer is negative. In years of growing production, the EEI will often give higher results; in years of decreasing production, a project-based method will often give a higher result. This clearly shows the dependency of the old (EEI) method on physical production levels. A possible solution would be to correct the EEI for the effect of capacity changes. To do so, one should have information on the relation between production level and specific energy consumption. This might give a better indication of the energy efficiency effect, but introducing corrections also affects the biggest advantage of the EEI method: the fact that it shows the development of the actual specific energy consumption. Therefore, to give a good indication of the development of energy efficiency, one should include all drivers. 
The two methods need different data to calculate the result. While energy data are used by both methods, energy efficiency index also uses production data, while the saving index uses project data to complete the calculation.

Q4: Which method is best for evaluating the results of a voluntary agreement?

It depends on the target of a policy instrument before one can conclude if a method based on project implementation is better than a method based on energy intensity. If one is interested in the actual development of the energy intensity, counting projects does not provide insight: savings by the implementation of projects alone do not give an accurate view on the development of both energy use and energy intensity. Implementation of saving projects gives only a partial explanation of development of energy use or intensity. A result based on projects alone therefore gives a too optimistic view. On the other hand, if one is interested in the impact of actions of participants, building a result on an energy efficiency index may lead to wrong conclusions as well. The dependency of the result on occupancy levels is better explained by the economic situation than the amount of energy-saving investments.

Participants themselves concluded that the new method better indicated the efforts of participants even though some sectors still wanted the possibility to use both the old and the new methods at the same time. The official goal of the Dutch LTA3 is an improvement of $30 \%$ energy efficiency improvement, defined as the ratio between the performance, service, goods or energy obtained and the energy supply for that purpose (NL Agency 2008). This goal is best represented by the (old) energy efficiency index. The (new) saving index represents a different development, as is shown in Decomposition analysis section. Ergo, the new monitoring method based on project savings, does not provide insight in the progress towards target achievement.

\section{Policy implications}

- In times of strong economic developments, the intensity approach has serious disadvantages, as it could conceal actual efforts on savings.

- The project approach has the drawback that it does not cover the (real) dissaving effects of lower occupancy rates for industrial processes.
- Population changes are the most important factor in the change in energy use of the LTA population. This is an issue that should be considered when observing results that have not been corrected. A population change can be the result of actual change in the number of companies (as is the case for the datacentres) but also of existing companies deciding to join (or leave) the program. For reliable trends, a correction should be made for population shifts

- Another drawback of the project approach is the large amount of data needed for a sound system for checking the real savings in the project approach. Despite the large amount of data in the project approach, more could be done to provide more reliable data and withhold participants from presenting nicer saving figures than actually realised. For many programs, it is unlikely that participants are willing to provide all the necessary data.

- Policy makers are more interested in the policy effect rather than the total saving effect. In other words, what savings are additional to those that would have occurred anyway? For both the old and the new methods, it is not possible with the available data to draw reliable conclusions on the additionality of the reported savings.

- For sound evaluation of a policy target, the monitoring result should be consistent with the set target. In LTA3, the consistency between set targets (intensitybased) and the actual monitoring and evaluation (project-based) is lost.

\section{References}

Abeelen, C., Harmsen, R., \& Worrell, E. (2013). Implementation of energy efficiency projects by Dutch industry. Energy Policy, 63(2013), 408-418.

AgentschapNL. (2009a). Verslag 17e Platformoverleg, d.d. 12 november 2009. Reference nr. 0919521/221/RvM/NW/ 156140 .

AgentschapNL. (2009b). Deelvoorstel correcties in MJA3. AgentschapNL, 15 september 2009.

AgentschapNL. (2010a). Memo 'Voorstel wijzigingen methodiek energie-efficiëntie MJA3', prepared for the LTA board February 3, 2010. Reference nr. 1021828/221/AL/156140.

AgentschapNL. (2010b). Memo 'Evaluatie monitormethodiek', prepared for the LTA board November 25, 2010. Reference nr. 1029216/221/CA/NW/156140.

AgentschapNL. (2011a). Memo 'Stand van zaken vergelijking oude versus nieuwe methodiek', prepared for the LTA board November 1, 2011. Reference nr. 1133837/223/MK/NW/ 156140. 
AgentschapNL. (2011b). Verslag Platform MJA3 overleg d.d. 1 november 2011. Reference nr. 1134584/221/RvM/NW/ 156140.

AgentschapNL. (2012a). Jaarverslag 2011 Energie Investerings Aftrek(EIA). Zwolle: AgentschapNL.

AgentschapNL. (2012b). Handreiking Monitoring, Version 2.2. Utrecht: NL Agency.

APERC. (2000). A study of energy efficiency indicators for industry in APEC economies. Japan: APERC.

Boonekamp, P. G. M. (2005). Improved methods to evaluate realized energy savings. PhD thesis. the Netherlands: Utrecht University.

Boonekamp, P. G. M. (2006). Evaluation of methods used to determine realised energy savings. Energy policy, 34, 39773922.

Boonekamp, P. G. M., Tinbergen, W., Vreuls, H. H. J., \& Wesselink, B. (2001). Protocol monitoring energy savings. Petten: ECN. ECN-C-01-129; RIVM 408137005.

Boßmann, T., Eichhammer, W., Elsland, R. (2012). Policy report: contribution of energy efficiency measures to climate protection within the European Union until 2050. Report for the German Federal Ministry for the Environment, Nature Conservation and Nuclear Safety (BMU). Fraunhofer Institute for Systems and Innovation Research ISI, Berlin/ Karlsruhe.

Bowie, R, \& Malvik, HV (2005). Measuring savings target fulfilment in the proposed directive on energy end-use efficiency and energy services COM(2003)0739. ECEEE summer study.

Boyd, G. A., \& Pang, X. A. (2000). Estimating the linkage between energy efficiency and productivity. Energy Policy, 28(2000), 289-296.

Bundgaard, S. S., Mikkelsen, K. D., Hansen Kjærbye, V., Togeby, M., Sommer, T., \& Larsen, A. E. (2013). Spending to save: evaluation of the energy efficiency obligation in Denmark. Toulon/Hyères, France: ECEEE summer study paper 7-13113.

Cahill, C., \& Ó Gallachoír, B. P. (2012a). Quantifying the savings of an industry energy efficiency programme. Energy Efficiency, 5, 211-224.

Cahill, C., \& Ó Gallachoír, B. P. (2012b). Combining physical and economic output data to analyse energy and $\mathrm{CO} 2$ emissions trends in industry. Energy Policy, 10, 422-429.

Canada, N. R. (2012). Improving energy performance in Canada. Canada: Office of Energy Efficiency Natural Resources.

CEN. (2007). Saving lifetimes of energy efficiency improvement measures in bottom-up calculations. Final CWA draft (CEN WS 27). Brussels: Comité Européen de Normalisation.

Das, M. C., Driessen, P. P. J., Glasbergen, P., Habermehl, N., Vermeulen, W. J. V., Blok, K., Farla, J. C. M., \& Korevaar, E. M. (1997). Evaluatie Meerjarenafspraken Over Energieefficiency. Utrecht: Universiteit Utrecht.

Eichhammer, W., \& Mannsbart, W. (1997). Indicators for a European cross country comparison of energy efficiency in the manufacturing industry. Energy Policy, 25, 7-9.

European Parliament \& Council. (2006). Directive 2006/32/EC of the European Parliament and of the Council of 5 April 2006 on energy end-use efficiency and energy services and repealing Council Directive 93/76/EEC. OJ L, 114, 64-85.
EVO (2014). International performance measurement and verification protocol. Washington, DC: Evaluation Valuation Organization. June 2014.

Farla, J., \& Blok, K. (2000). The use of physical indicators for monitoring of energy intensity developments in the Netherlands 1980-1995. Energy, 25(7), 609-638.

Farla, J., \& Blok, K. (2001). The quality of energy intensity indicators for international comparison in the iron and steel industry. Energy Policy, 29, 523-543.

Farla, J., \& Blok, K. (2002). Industrial long-term agreements on energy-efficiency in the Netherlands. A critical assessment of the monitoring methodologies and quantitative results. $J$ Clean Prod, 1, 165-182.

Freeman, S. L., Niefer, M. J., \& Roop, J. M. (1997). Measuring industrial energy efficiency: practical issues and problems. Energy Policy, 25(7-9), 703-714.

Grobler, L. J. (2010). Measurement and verification of energy efficiency savings in industrial facilities: the flaw of using energy intensities to determine savings. Energy Engineering, 107(5), 24-41.

Hendriksen B, van der Kolk J (2013). Resultaten en vooruitzichten Energie-efficiëntie MEE bedrijven in Nederland. Evaluatie Meerjaren afspraken energie efficiëntie MEE. Amsterdam: KPMG Sustainability.

IEA. (2014). Key world energy statistics. Paris: International Energy Agency.

Leutgöb, K., Reichl, J., \& Kollmann, A. (2011). Making the results of bottom-up energy savings calculations comparable (ECEEE 2011 summer study 6-11 June 2011). France: Belambra Presqu'île de Giens.

Montgomery, WD (2014). Voluntary action in present and future climate policy. Presentation at the International symposium on voluntary approaches. Tokyo, Japan: NERA Economic Consulting.

Neelis, M., Ramirez, A., Patel, M., Blok, K., Farla, J., \& Boonekamp, P. (2007). Energy efficiency developments in the Dutch energy-intensive manufacturing industry, 1980 2003. Energy Policy, 35(12), 6112-6131.

NL Agency (2008). Long-term agreement on energy efficiency 2001-2020. Final Version. 13 June 2008, The Hague: NL Agency.

OECD. (2003). Voluntary approaches for environmental policies, effectiveness, efficiency and use in policy mixes. Paris: OECD.

Phylipsen, G. J. M., Blok, K., \& Worrell, E. (1997). International comparisons of energy efficiency - methodologies for the manufacturing industry. Energy policy, 25(7-9), 715-725.

Pizer, W. A., Morgenstern, R., \& Shih, J. (2011). The performance of industrial sector voluntary climate programs: climate wise and 1605(b). Energy policy, 39(2011), 7907-7916.

Ramirez, C. A., Patel, M., \& Blok, K. (2005). The non-energy intensive manufacturing sector. An energy analysis relating to the Netherlands. Energy, 30, 5,749-767.

Rezessy, S., \& Bertoldi, P. (2011). Voluntary agreements in the field of energy efficiency and emission reduction: review and analysis of experiences in the European Union. Energy Policy, 39(2011), 7121-7129.

Rietbergen, M. G., Farla, J. C. M., \& Blok, K. (2002). Do agreements enhance energy efficiency improvement? Analysing the actual outcome of long-term agreements on industrial 
energy efficiency improvement in the Netherlands. J Clean Prod, 10, 155-163.

Saygin, D., Worrell, E., Patel, M. K., \& Gielen, D. J. (2011). Benchmarking the energy use of energy-intensive industries in industrialized and in developing countries. Energy, 36(2011), 6661e6673.

Staniaszek D, Lees, E (2012). Determining energy savings for energy efficiency obligation schemes. Montpelier, Vermont: ECEEE, RAP.

Tanaka, K. (2011). Review of policies and measures for energy efficiency in industry sector. Energy policy, 39(2011), 6532-6550.

Verdonk, M., \& Boonekamp, P. G. M. (2009). Vergelijking methoden energiebesparing: PME en MJA. Petten: ECN.

Volkerink, B., Meindert, L., van der Wagt, M., de Groot, H. L. F., Bolscher, H., Slingerland, S., Reynes, F., Jonkhof, W., Ivanova, O., \& Bulavskaya, T. (2013). Evaluatie Meerjarenafspraken Energie Efficiëntie 2008-2020. Rotterdam: Ecorys.
Vreuls, H., \& Zijlema, P. (2013). Nederlandse lijst van energiedragers en standaard $\mathrm{CO}_{2}$-emissiefactoren, version February 2013. Utrecht/Sittard: AgentschapNL.

Vreuls, H., De Groote, W., Bach, P., Schalburg, R., DyhrMikkelsen, K., Bosseboeuf, D., Celi, O., Kim, J., Neij, L., \& Roosenburg, M. (2005). Evaluating energy efficiency policy measures \& DSM programmes - volume I: evaluation guidebook. Report for the IEA-DSM task IX.

Worrell, E., Cuelenaere, R. F. A., Blok, K., \& Turkenburg, W. C. (1994). Energy consumption by industrial processes in the European Union. Energy, 19(11), 1113-1129.

Worrell, E., Price, L., Martin, N., Farla, J., \& Schaeffer, R. (1997). Energy intensity in the iron and steel industry: a comparison of physical and economic indicators. Energy policy, 25, 727744.

WRI (2014). Greenhouse Gas Protocol. Policy and Action Standard. Washington, DC: World Resources Institue, ISBN 978-1-56973-840-5. 